\title{
Factors Affecting the Circumcision Decision
}

\author{
Jeffrey D. Tiemstra, $M D$
}

Background: Studies from more than 10 years ago have shown that most parents choose circumcision for their infant sons for nonmedical reasons. Since then a wealth of data has accumulated on the relative risks and benefits of the procedure, although the medical community remains divided on the appropriateness of the procedure. Whether the ongoing research effort and medical debate have had an effect on parental decision making is unknown.

Methods: A survey of parents of 55 male infants was conducted to determine when the parents made their decision regarding circumcision, whether discussions with providers affected their decisions, and what the reasons were for their decisions.

Results: Eighty percent of parents made the circumcision decision before provider discussions. Seventeen percent reported changing their mind based on their provider's discussion, although it did not significantly affect the circumcision rate. Eighty-three percent of parents reported their provider's attitude as neutral, including 7 of 8 patients who changed their mind based on the discussion; only 1 patient was circumcised based on the provider's recommendation. Predominant reasons for circumcision were ease of hygiene (67 percent), ease of infant circumcision compared with adult circumcision (63 percent), medical benefit (41 percent), and father circumcised ( 37 percent). Reasons for no circumcision included unnecessary ( 73 percent), painful (36 percent), and father uncircumcised (18 percent).

Conclusions: Most parents have made a decision on circumcision before physicians discuss it, and physician discussions appear to have little impact on the decision. Ease of cleanliness is still the most common reason parents choose circumcision. (J Am Board Fam Pract 1999;12:16-20)

After decades of debate and study, the appropriateness of routine male circumcision remains uncertain. Potential benefits traditionally cited include reduced risks of penile cancer, sexually transmitted disease, and infant urinary tract infection. ${ }^{1-13}$ Some studies have challenged these potential benefits, however, and critics of routine circumcision have questioned the degree of risk involved for a strictly preventive procedure. ${ }^{14-23}$ Given these uncertainties, in 1989 the American Academy of Pediatrics (AAP) modified its earlier statements opposing routine circumcision ${ }^{24-26}$ and emphasized instead the importance of informing parents of both sides of the debate: "newborn circumcision has potential medical benefits and advantages as well as disadvantages and risks. When circumcision is being considered, the benefits and risks should be explained to the parents and informed consent obtained." 9

Submitted, revised, 8 June 1998

From the Family Health Center, Provena Saint Joseph Medical Center, Napierville, Ill. Address reprint requests to Jeffrey D. Tiemstra, MD, Provena Saint Joseph Family Health Center, 24024 West Brancaster Dr, Napierville IL 60564.
Studies done before 1989 clearly have shown that few parents were aware of the medical debate regarding circumcision, and most based their choice on concerns relating to hygiene and appearance. ${ }^{27,28}$ From 1983 to 1987 four separate trials tested formal educational interventions aimed at discouraging circumcision. ${ }^{29-32}$ Only one showed a small reduction in the circumcision rate ( 72 versus 94 percent), but none showed any improvement in parents' understanding of the medical issues involved despite the wide range of education levels. In one study the educational intervention not only was ineffective but also increased parental dissatisfaction with care. Only one study specifically addressed the timing of the decision, ${ }^{33}$ and found that 56 percent of women chose circumcision even before becoming pregnant. Since the AAP's 1989 statement emphasizing the informed consent process, no one has revisited the issue of how or when parents decide whether to have their sons circumcised.

The goal of this study was to determine whether the medical debate has had an impact on parents' decision making. Rather than looking at the content of the consent process and decision 
from the provider's viewpoint, I chose to look at the discussion and decision from the parents' viewpoint by asking the following questions: (1) when do parents make the circumcision decision, (2) when do parents discuss circumcision with their physician, (3) does the discussion have any impact on the decision, and (4) what are the reasons for their decision? The timing of the circumcision decision relative to the discussion with the physician was of particular interest. If social concerns were more important, it would seem likely that the decision would be apparent well in advance of prenatal and neonatal health care encounters, as, indeed, was the case 14 years ago. Conversely, if medical concerns were important, then it would seem more likely that parents would be open to physicians' discussions and make the final decision after those discussions.

\section{Methods}

A 13-item questionnaire was distributed at two family practice clinics during a 6-month period. Parents of all male infants younger than 6 months of age coming for well-child care on select days (determined by staff availability) were approached by a nurse or physician-researcher (not their own care provider) and asked to complete the form. The completed form was collected when the parents left the waiting room for their infant's examination. Eight questions were directed at the decision-making process and timing, with multiple choice or yes-no responses, and 3 questions asked about religion and location of prenatal care. The last 2 questions offered a list of reasons for deciding for or against circumcision, and respondents were asked to check all that applied as well as indicate the most important reason. Analyses of the timing of the decision versus the timing of the discussion was performed by the chi-square test ( $3 \times 3$ table: before, during, or after the pregnancy). Circumcision rates for parents affected or unaffected by the physicians' discussion was also compared by the chi-square test.

\section{Results}

Fifty-five surveys were completed. No parent refused to participate, but 3 surveys were returned uncompleted. Forty-two parents (76 percent) were seen at site $\mathrm{A}$ and belonged to an health maintenance organization through an employer or university; of these 23 (42 percent of total) re-

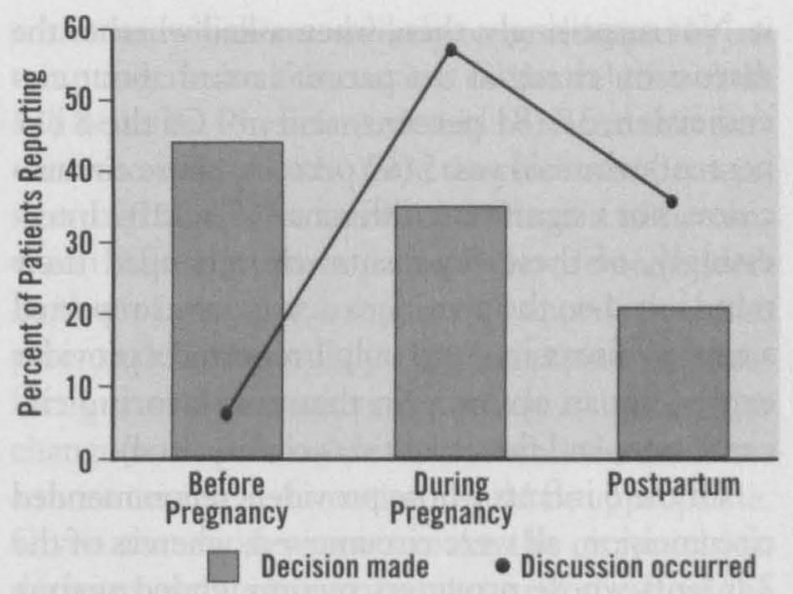

Figure 1. Decision timing versus discussion timing.

ceived prenatal care from a private obstetrician or nurse midwife, and 19 (35 percent of total) received prenatal care from a family physician. The remaining 13 participants ( 24 percent) were seen at site B, a community health center for patients without insurance or on public assistance; of these 10 had received their prenatal care from a nurse midwife, and 3 listed other clinics. Respondents named 21 different physicians or nurse midwives as their providers, representing 7 different clinics. The most frequently reported provider had $7 \mathrm{pa}-$ tients, and the next most frequent 4 patients; thus the sample was not skewed by the practice of any single provider. Forty-four ( 80 percent) infants had been circumcised.

\section{Timing of the Decision}

Most parents appear to make the circumcision decision early. Twenty-four (44 percent) reported making the decision before getting pregnant, but only 4 (7 percent) had discussed circumcision with a provider prenatally. Of the 19 (35 percent) who made the decision during pregnancy, 8 reported doing so in the first trimester. Consequently, most parents $(37,80$ percent) reported making the decision before discussing circumcision with their provider. Figure 1 graphically illustrates this significant discrepancy between the timing of the circumcision decision and the discussion with the physician $(P<0.005)$.

\section{The Provider's Role in the Decision}

Regarding the character of the provider's discussion, 38 of 46 respondents ( 83 percent) described a neutral process, with 6 (13 percent) having it recommended and 2 ( 4 percent) being advised against 
it. Not surprisingly, then, when asked whether the discussion changed the parent's mind about circumcision, 38 ( 83 percent) said no. Of the 8 (17 percent) who said yes, 5 (62 percent) chose circumcision, not a significant difference $(P>0.10)$. Interestingly, of these 8 parents who changed their mind based on the provider's discussion, 7 reported a neutral discussion, and only 1 reported a provider expressing an opinion (in that case favoring circumcision, and that infant was circumcised).

Of the 6 infants whose providers recommended circumcision, all were circumcised, whereas of the 2 infants whose providers recommended against circumcision, only 1 was not. Seven of these 8 parents reported making their decision before the provider's discussion; only 1 chose circumcision postpartum after having it recommended.

\section{Reasons for the Decision}

Table 1 illustrates the relative ranking of reasons for choosing circumcision. Patients were allowed to check all applicable reasons and then asked to choose the most important, if possible. Consistent with past studies, hygiene and preventing the procedure at a later age were the most important factors for parents, with other social concerns being less important. In contrast to past studies, however, medical benefits were reported more often as reasons for circumcision.

Table 1. Reasons Parents $(n=44)$ Chose Circumcision.

\begin{tabular}{lccc}
\hline Reason* & Number & Percent & $\begin{array}{c}\text { Most } \\
\text { Important }\end{array}$ \\
\hline $\begin{array}{l}\text { It's easier to keep the } \\
\text { penis clean }\end{array}$ & 31 & 67 & 18 \\
$\begin{array}{l}\text { It's easier to do it now than } \\
\text { when he's older }\end{array}$ & 29 & 63 & 8 \\
$\begin{array}{l}\text { Medically, it's better to be } \\
\text { circumcised }\end{array}$ & 19 & 41 & 10 \\
$\begin{array}{l}\text { The baby's father is } \\
\text { circumcised }\end{array}$ & 17 & 37 & 1 \\
$\begin{array}{l}\text { My physician recommended it } \\
\begin{array}{l}\text { My son should be like the } \\
\text { other boys }\end{array}\end{array}$ & 6 & 13 & - \\
$\begin{array}{l}\text { Its important in my religion } \\
\text { Other }\end{array}$ & 5 & 11 & 1 \\
$\quad \begin{array}{l}\text { Appearance } \\
\text { Culture }\end{array}$ & 2 & 5 & 2 \\
$\begin{array}{l}\text { Family pressure } \\
\text { Father insisted }\end{array}$ & 1 & 2 & 1 \\
\hline
\end{tabular}

*Respondents were asked to check as many as applied. $\dagger$ Not all respondents marked a most important reason.
Table 2. Reasons Parents $(n=11)$ Refused Circumcision.

\begin{tabular}{|c|c|c|c|}
\hline Reason* & Number & Percent & $\begin{array}{l}\text { Most } \\
\text { Important }\end{array}$ \\
\hline It's just not necessary & 8 & 73 & 6 \\
\hline It's painful for the baby & 4 & 36 & 1 \\
\hline $\begin{array}{l}\text { The baby's father is not } \\
\text { circumcised }\end{array}$ & 2 & 18 & 1 \\
\hline Not sure & 2 & 18 & 1 \\
\hline \multicolumn{4}{|l|}{ Other } \\
\hline $\begin{array}{l}\text { Hospital failed to do it } \\
\text { after birth }\end{array}$ & 1 & 9 & 1 \\
\hline $\begin{array}{l}\text { Medically its better not to be } \\
\text { circumcised }\end{array}$ & 0 & 0 & - \\
\hline My physician advised against it & 0 & 0 & - \\
\hline I never thought about it & 0 & 0 & - \\
\hline
\end{tabular}

*Respondents were asked to check as many as applied.

†Not all respondents marked a most important reason.

Religious requirement for circumcision was not a significant factor in this sample: only 2 patients (4 percent) belonged to religious groups who require circumcision (Judaism, Islam), and only these 2 patients cited religion as their primary reason for choosing circumcision (although 3 Christians checked religion as a secondary reason). Most parents reported their religion as Christian (42, 76 percent); 9 (16 percent) reported no religious affiliation; and 1 each (total 4 percent) reported Hinduism and Buddhism.

Reasons for avoiding circumcision are ranked in Table 2. No parents reported thinking the uncircumcised state was medically better; rather, most believed it was simply unneccessary. Parents did not report the father's status as important in the decision very often; however, of 8 infants with reportedly uncircumcised fathers, only 2 were circumcised.

\section{Discussion}

Although this study is clearly limited by the small and heterogenous sample, the findings are consistent with those of studies from 15 years ago, which showed (1) that the circumcision decision is most often made before parents discuss the issue with their care providers, (2) that social concerns are more important than medical ones, and (3) that providers' discussions have limited impact on the decision made. Medical benefits were cited more frequently in this study than in past studies, although medical issues remain secondary to hygiene and convenience. Given the limitations of 
this study, the minor increase in parents citing medical issues might or might not be important. The study design could have contributed to this finding as well, because the mere presence of this item on the survey could have prompted parents to choose it.

If this change is real, then advocates of circumcision might argue that parents are correctly interpreting the medical information given them. It is also possible, however, that parents are choosing the data that support their earlier decision, or that physicians' neutral discussions of circumcision might be subtly biased to support the parents' earlier decision. Two of the 8 physicians who offered a recommendation had more than 1 patient in the study, and both were reported by another patient to provide a neutral discussion. Thus, neutral discussions of circumcision can be influenced by parents' previous decisions, whether in the provider's content or presentation or the parent's perception.

Parents choosing against circumcision did not display strong beliefs that being uncircumcised was in any way better or healthier; they simply saw circumcision as unnecessary. An uncircumcised father appeared to be a strong predictor of the choice, although it is unclear how this fact affected the parents' decision-making process. Because these parents did not rate the father's status as important, having a similar appearance is probably not the issue. Perhaps experience with an adult man who is successfully uncircumcised might demonstrate to the parents that the procedure is unnecessary. This finding also raises the question of whether parents are being provided with information about the potential medical benefits of not being circumcised.

The multiple-choice design used in this study could have introduced another bias in this study by forcing parents to make a decision. This format assumes that parents had some level of information, at least about the choices they indicated, when in fact parents might have had very little information to guide their decision. Thus while some conclusions can be made regarding the relative weight of social versus medical concerns, nothing can be inferred from this study regarding the depth of understanding of circumcision issues by the respondents.

In summary, then, this study suggests that parents continue to have preformed decisions regarding circumcision based primarily on nonmedical concerns, which are unlikely to be changed by attempting neutral discussion of the relative risks and benefits. Physicians should be aware that parents who have already made the circumcision decision might perceive a neutral discussion of circumcision differently from parents who are undecided. In the former case a supportive approach to the parent's decision could yield greater parental satisfaction, as a persuasive approach is unlikely to change most parents' decisions, while in the latter a more complete discussion would be appropriate. Given that most parents make the circumcision decision early, physicians who wish to affect the decision should consider discussing it at preconception visits or early in prenatal care. Regardless of the extent of the discussion informing the parents' choice, if circumcision is chosen, informed consent noting the specific immediate risks of the procedure must still be obtained.

\section{References}

1. Wiswell TE. Circumcision circumspection. N Engl J Med 1997;336:1244-5.

2. Schoen EJ. The relationship between circumcision and cancer of the penis. CA Cancer J Clin 1991;41: 306-9.

3. Swafford TD. Circumcision and the risk of cancer of the penis. Am J Dis Child 1985;139:112.

4. Kochen M, McCurdy S. Circumcision and the risk of cancer of the penis. A life-table analysis. Am J Dis Child 1980;134:484-6.

5. Simonsen JN, Cameron DW, Gakinya $M N$, NdinyaAchola JO, D'Costa LJ, Karasira P, et al. Human immunodeficiency virus infection among men with sexually transmitted diseases. Experience from a center in Africa. N Engl J Med 1988;319:274-8.

6. Smith GL, Greenup R, Takafugi ET. Circumcision as a risk factor for urethritis in racial groups. Am J Public Health 1987;77:452-4.

7. Parker SW, Stewart AJ, Wren MN, Gollow MM, Straton JA.. Circumcision and sexually transmissible disease. Med J Aust 1983;2:288-90.

8. Taylor PK, Rodin P. Herpes genitalis and circumcision. Br J Vener Dis 1975;51:274-7.

9. Schoen EJ, Anderson G, Bohon C, et al. Report of the task force on circumcision. American Academy of Pediatrics Task Force on Circumcision. Pediatrics 1989;84: 388-91.

10. Wiswell TE, Miller GM, Gelston HM, Jones SK, Clemmings AF. The effect of circumcision status on periurethral bacterial flora during the first year of life.J Pediatr 1988;113:442-6.

11. Wiswell TE, Enzenauer RW, Holton ME, Cornish 
JD, Hankins CT. Declining frequency of circumcision: implications for changes in the absolute incidence and male to female sex ratio of urinary tract infection in early infancy. Pediatrics 1987;79:338-42.

12. Wiswell TE, Smith FR, Bass JW. Decreased incidence of urinary tract infections in circumcised male infants. Pediatrics 1985;75:901-3.

13. Ginsburg CM, McCracken GH Jr. Urinary tract infections in young infants. Pediatrics 1982;69:409-12.

14. Maden C, Sherman KJ, Beckman AM, Hislop TG, Teh CZ, Ashley RL, et al. History of circumcision, medical conditions, and sexual activity and risk of penile cancer. J Natl Cancer Inst 1993;85:19-24.

15. McCance DJ, Kalanche A, Ashdown K, Andrade L, Menezes F, Smith P, et al. Human papillomavirus types 16 and 18 in carcinomas of the penis from Brazil. Int J Cancer 1986;37:55-9.

16. Gee WF, Ansell JS. Neonatal circumcision: a tenyear overview. Pediatrics 1976;58:824-7.

17. Laumann EO, Masi CM, Zuckerman EW. Circumcision in the United States. Prevalence, prophylactic effects, and sexual practice. JAMA 1997;277:1052-7.

18. Smith GL, Greenup R, Takafuji ET. Circumcision as a risk factor for urethritis in racial groups. Am J Public Health 1987;77:452-4.

19. Harkavy KL. The circumcision debate. Pediatrics 1987;79:649-50.

20. King LR. Neonatal circumcision in the United States in 1982.J Urol 1982;128:1135-6.

21. Preston EN. Whither the foreskin? a consideration of routine neonatal circumcision. JAMA 1970;213: 1853-8.

22. Morgan WK. "Penile plunder." Med J Aust 1967;1: 1102-3.
23. Lawler FH, Bisonni RS, Holtgrave DR. Circumcision: a decision analysis of its medical value. Fam Med 1991;23:587-93.

24. Guidelines for perinatal care. Evanston, Ill: American Academy of Pediatrics/The American Academy of Obstetricians and Gynecologists, 1983.

25. Thompson HC, King LR, Knox E, Korones SB. Report of the ad hoc task force on circumcision. Pediatrics 1975;56:610-1.

26. American Academy of Pediatrics, Committee on Fetus and Newborn. Standards and recommendations for hospital care of newborn infants. 5th ed. Evanston, Ill: American Academy of Pediatrics; 1971.

27. Brown MS, Brown CA. Circumcision decision: prominence of social concerns. Pediatrics 1987;80: 215-9.

28. Lovell JE, Cox J. Maternal attitudes toward circumcision. J Fam Pract 1979;9:811-3.

29. Christensen-Szalanski JJ, Boyce WT, Harrell H, Gardner MM. Circumcision and informed consent: is more information always better? Med Care 1987; 25:856-67.

30. Rand CS, Emmons CA, Johnson JW. The effect of an educational intervention on the rate of circumcision. Obstet Gynecol 1983;62:64-8.

31. Maisels MJ, Hayes B, Conrad S, Chez RA. Circumcision: the effect of information on parental decision making. Pediatrics 1983;71:453-5.

32. Herrera AJ, Cochran B, Herrera A, Wallace B. Parental information and circumcision in highly motivated couples with higher education. Pediatrics 1983;71:233-4.

33. Bean GO, Egelhoff C. Neonatal circumcision: when is the decision made. J Fam Pract 1984;18:883-7. 